The Geneva Papers on Risk and Insurance, 20 (No. 76, July 1995), 439-445

\title{
From Insurance State to Welfare State, and Back Again?
}

\author{
by Bert de Vries*
}

\section{Summary}

In the Middle ages social security was largely a matter for the guilds. When the guilds were abolished, insurance companies partly assumed this responsibility. Later, the Government demanded that it should take over. Now, the key question is how responsibilities can be divided between the public and the private sector. Lessons from history.

\section{Lessons from history}

'Those who fail to learn from history are doomed to repeat it endlessly', is a wellknown saying. To avoid this repetition, I shall focus in this paper on the historical development of social security'.

The title suggests a pendulum movement. We came from the insurance state, forged ahead to the welfare state and are now at the point of turning back. What can we learn from history in this context? First of all, that a certain form of insurance, state did exist prior to the welfare state. The basis was created in the period in which the guilds played a significant role in the Netherlands. That was from the end of the fourteenth century until the French era, when guilds were prohibited.

One of the advantages of membership of a guild was that it also opened up membership of the benevolent funds that had been set up by most guilds. Participation, it should be noted, was obligatory, as was payment of contributions. The guilds were also assigned

*The author is Chairman of the Executive Committee at the Social Insurance Bank, Professor at the Erasmus University of Rotterdam and former Minister of Social Affairs and Employment, Netherlands.

${ }^{1}$ A significant proportion of the following analysis is based on E.J. Fischer Care insurance in the Netherlands from the late Middle Ages to the end of the 19th century, an overview, an address delivered during the Netherlands Insurance Association symposium on 'The past as springboard' December 9 th 1994, Zeist. 
duties under public law. The importance of this delegation of responsibility by the government was that it reduced claims on the municipal poor funds.

In addition to what were termed guild benevolent funds, there were also neighbourhood benevolent funds, servants' benevolent funds, benevolent funds for Jews who had emigrated to the Netherlands, Huguenots, etc. In many cases these mutual insurances offered broad coverage i.e. not only claims in the event of death and illness, but also disability and old age along with payments to widows and orphans.

Estimates indicate that around 1750 between 25 and $35 \%$ of the population was a member of a sick fund, which - as it was termed - contributed to the pride and independence of the workers, as they were not dependent upon alimonies for the poor, Church poor relief or Church social welfare work. The fact that more was involved than insurance against illness, emerges from the study by Van Abeelen of two and a half centuries of sickness relief funds. 'The servants' benevolent fund was therefore more than the sickness fund of today for the family of the worker in the eighteenth century; for him it was an insurance institution for virtually all the contingencies he faced at the time.'2

The situation was different in the nineteenth century. The guild benevolent funds disappeared along with the guilds. The poor economic situation, however, led at the same time to a sharp increase in the claims on social security. In the province of Twente there were municipalities in which between $30 \%$ and $40 \%$ of the population had to resort to poor relief. Even then National Assistance had a heavy burden to carry.

In that period many servants' benevolent funds, which were allowed to continue to exist, disappeared. In most cases they lacked professional management. There was no proper allocation of costs; actuaries did not yet exist. Furthermore, they increasingly experienced competition from new insurers who were specialised in a much narrower range of services. In that situation, servants' benevolent funds could not cope with the mass claims being made on them in the first half of the last century in particular.

At the same time, however, a number of insurance companies were set up in this period, which began to flourish and develop into powerful modern companies. One example is the Let op uw Einde Funeral Fund, literally 'pay heed to your end', from which emerged the Utrecht insurance company and later still the FORTIS AMEV insurance company. By the end of the last century a reasonably well developed insurance system had evolved, which, however, differed from the guilds and servants' benevolent funds in a number of respects.

Rather than broad coverage, specialist insurances were generally offered. Mutual forms of insurance made way for commercial forms of insurance. The organisations grew from local to national in scale. That does not mean, however, that all risks were insurable, even less that the majority of employees availed themselves of the insurance options on offer. Large industrial companies in particular frequently set up factory funds, but this covered only a small proportion of the workers and then only for the term of their employment with the company. For the rest, the wages earned by many workers were still too low and their horizon too short to avail themselves of the insurance provisions.

${ }^{2}$ E.I.J. van den Abeele. Two and a half centuries of health insurance fund. The Hague, 1959. 
Against this background, discussion was launched at the end of the last century and the early part of this century on whether the Government should assume responsibility for introducing a number of social insurances to cover all employees. The anti-revolutionary minister Talma stated that it should. As the legal grounds for Government intervention in introducing the Sickness Benefit Act and the Disablement Benefit Act, he adduced: 'Insurance against the monetary consequences of the eventualities of life is connected with the method of production. The trend in the method of production is accompanied for the worker by a reduction in a secured means of livelihood, whilst in addition the relationship between employer and employee has changed entirely as a result of the loosening of the personal ties. It is now the task and the right of Government to ensure that the relationships that it has to protect and maintain - for the public at large or part of it - do not entail any consequences that undermine the public's sense of justice and thus .... threaten its own existence.

It is at odds with the sense of justice if a worker who has worked as long as he can is dependent upon the assistance of third parties at the moment he can no longer work. It is therefore not only desirable but from a social point of view fundamental that in general the conditions of employment of people in salaried employment are organised in such a way that their needs in the event of illness or disability are also taken into account. It is therefore a matter of fairness that wages also suffice to provide a livelihood, not only in the period when they are able to work but also when illness or disability prevent them working.'

This long quotation immediately brings us to two key elements in the system:

- in the event of an employee falling ill or becoming disabled there must be a guarantee that at least a proportion of the wage continues to be paid;

- and that the Government must ensure that things are organised effectively.

The latter point did not directly mean that the insurances would also have to be implemented by the Government. There was heated political discussion on this point in the early decades of this century. Ultimately, it resulted in the compromise that the Government would be responsible for the policy conditions and - in the last instance financing, while the two sides of industry would be responsible for implementation in bipartite industrial insurance boards.

The principles adopted by Talma were ratified during the Second World War by the Van Rhine Commission when it stated: 'The community, organised in the State, is responsible for the social security and provision against want of all its members, subject to the condition that these members themselves make reasonable attempts themselves to secure social security and provision against want.'

This wording goes beyond that of Talma in two respects. It does not confine itself to the employees category, nor to certain categories of risk. The basis was created for a comprehensive system of social security, which was ultimately anchored in Section 20 of the Constitution. It reads as follows: 
1. The secured means of livelihood of the population and the distribution of prosperity are matters of Governmental concern.

2. The law shall set rules governing the claims on social security.

3. Dutch citizens in the country, who are unable to provide for themselves, have a statutory right to assistance from the Government.

\section{Extending the Welfare State}

The pace at which the welfare state was developed after the Second World War cannot be seen in isolation from the reconstruction and strong compartmentalisation of society. Improvements to the social security system represented a major prerequisite for obtaining a cooperative stance from the trade unions towards wage controls. Furthermore, the denominational parties felt a need to prove that the fate of the weaker members of society was not only in good hands with the social democrats.

Thus it was that a very comprehensive system with easy access and favourable policy conditions came about. Two further causes may be cited for the greater ease of access. First, there was the strong need in the post-war period to make the public aware that claiming social security should not be felt as a favour but as a right. The second was that responsibility for implementing the employee insurances - as indicated above - was detached from the responsibility for legislation and financing. In itself this choice did not appear unreasonable. The two sides of industry at industry level not only had an interest in proper cost control, but also appeared to offer the best potential for ensuring that there were no unnecessary insurance claims.

The more organised this worker solidarity became, the more anonymous the system became and, as the Parliamentary inquiry by the Buurmeijer Commission revealed, cost control and supervision fell more and more by the wayside. Worse still, the scope afforded by the laws was used more and more as a means of resolving difficulties between employers and employees. This was facilitated by the fact that frequently, at micro level, no relationship was sensed between the scale of the loss and contribution levels.

\section{The Welfare State crisis}

Apart from a flexible assessment of claims, the favourable policy conditions were also reflected in high benefit percentages, a long period of payment of benefits and a high subsistence benefit level.

From the early eighties onwards, however, the arrangements provided by the welfare state came under increasing pressure. The causes were partly economic, partly social in nature and partly a result of unsuspected side effects of the system.

The stagnation in the trend in employment in the seventies was economic in nature, to be followed by a fall in absolute terms in the early eighties. That led to an explosion in the claims on disability and unemployment insurances.

The trends towards equal rights and individualisation, both of which led to a sharp growth in the number of claimants eligible for their own income, was social in nature. In so 
far as the capacity of the labour market to absorb people fell short of meeting the need in the form of a paid job, benefits were usually claimed. To this was added the impact of the ageing of the population.

The side effects aspect can be ascribed to a significant degree to the success of the 'From favour to right' campaign. This awareness of entitlement gradually came to be detached from being insured. The feeling of being insured on the basis of paying contributions gradually changed into a sense of having a democratic right to assistance from the State if one felt unable to provide for oneself (see also Schuyt). Not only was this right assumed, but people started calculating how best to benefit most from the arrangement. This evolution was perceptible among employers and employees alike.

The result of this complex of causes was that the relationship between the numbers entitled to benefit and the numbers paying contributions became ever more unfavourable. In 1970 there were still 46 with benefit entitlement to every 100 in work, the figure had risen to 65 by 1980 and to 83 by 1984 . We seem to be rocketing towards a one-to-one relationship. The system was not set up to cater for this. Financing the costs meant an ever greater claim on the national income. This in turn resulted in processes of passing costs on, which were damaging the economy. A vicious spiral downwards thus came about.

\section{Moves towards reform}

The modifications enforced by these developments can be divided into two categories. The first category relates to emergency measures which have no other purpose than restricting costs. Examples include cuts to such provisions as child allowance on pensioners with a younger partner.

The second category relates to modifications aimed at influencing behaviour to reduce claims on the system. This category includes such measures as reducing the level of benefit for disability and unemployment from $80 \%$ and $75 \%$ to $70 \%$ of last earnings. Measures to hamper access such as scrapping the offsetting of unemployment and introducing the concept of 'suitable work' in the Disablement Benefits Act (WAO) come into this category, as do the tightening of the criteria for length of previous consecutive employment and working record under the Unemployment Benefits Act.

The distinction between the two categories is not always clear, it must be said. In many cases both are pursuing the same objective. For example, the freezing and decoupling measures of the past fifteen years were aimed not only at controlling costs, but also at reinforcing the financial incentives to look for a job or to keep that job as long as possible.

A third characteristic may also come into play - the decollectivisation of costs. For example, the introduction of a period of two to six weeks in the Sickness Benefit Act before entitlement commences has no impact on the commitment of employers to continue to pay wages. To that extent all that occurs is a shifting of costs from the public to the private sector. That only leads to lower labour costs if the new distribution of responsibilities induces less absenteeism and lower costs of implementation. It is here that the social merit of the measure lies. Politically, the situation may be different if the size of the public sector becomes a sensitive criterion, or the need emerges to dump part of the unresolved 
problem into the private sector's lap. An additionally critical stance in assessing privatisation proposals is therefore called for.

Despite the unexpectedly large growth in employment and the measures aimed at controlling costs and the number of claims, the ratio of claimants to contributors hardly fell at all during the eighties and actually rose in the early nineties as a result of the recession. The claim made by social security on the national income has also dropped hardly at all. The Government has acquired the reputation - as a result of all the interventions and the political and social discussion of the subject - of being an unreliable insurer, with the policy setting forth the terms hardly being worth the paper its written on.

As a result of the ongoing ageing of the population and individualisation, upward pressure on the claimants/contributors ratio will continue in the future. At the same time, it will become more difficult to safeguard the affordability of the system with a policy of freezing and decoupling measures. The fact is that those who are dependent upon the minimum wage or largely dependent upon an old age pension will come to lag ever further behind.

More far-reaching privatisation of the Sickness Benefit Act and the job disability insurance schemes is a sensitive operation in this situation. Claims on these provisions still outstrip those in our neighbouring countries. Better control of the volume of claims is essential. What scope will be given to private insurers to implement this task?

\section{What scope is to be given to the Insurance State?}

Does privatisation imply that the Government must distance itself from its responsibility for guaranteeing that every employee is entitled to the continued payment of a substantial part of his or her wages in the event of illness or disability? It is unlikely that on this point the Government will depart from the views of Minister Talma and the Van Rhine Commission. The proposal to privatise the Sickness Benefit Act was therefore accompanied by the announcement that the commitment in the Civil Code to continue payment of wages will be sustained.

In the event of disability, too, the intention is to continue to provide statutory guarantees of the level and duration of current agreements. This would appear to mean continuing with a situation in which the responsibility for financing has been detached to a significant degree from the possibility of influencing costs. With the difference that costs will not in future be for the legislators but for the implementer, in this case the private insurer.

The results from policy to reduce the volume of claims will mainly come from applying measures that are part and parcel of the tool chest of private insurers. Will they, however, be permitted to actually use these tools or will they encounter major social and perhaps political resistance? This risk is by no means imaginary if insurers regard their policy as a commercial contract, with a particular product being supplied at a commercial price on the basis of mutual consent, while the public regards the insurance primarily as a social contract which meets an essential need and which therefore should be available to all at an affordable price. 
Tensions may readily emerge here. The first possible cause is that insurers - in an effort to reduce incurred claims and under pressure from competition - may decide on a significant differentiation in contributions based on classification into risk categories. Even if the differentiation in contributions remains within limits - a band width of $1: 2.5$ has been mentioned - this could lead to significant differences in labour costs between employers in the highest and lowest risk categories. Apart from better policy in the field of employment conditions and sickness absence, it may result in a more rigorous selection based on sickness risks when employing staff. What are the chances for reintegration of the partially disabled, who suffer a greater than average risk of being absent through sickness? The employers involved will be inclined to pass on to the insurers the blame for their greater reluctance and the latter will say that they have no other option. Both are running a severe risk, however, of being pilloried by society and the political establishment alike.

One not improbable reaction is that employers will be only too happy to meet the trade unions wishes for the full privatised risk being insured collectively again in the collective agreement and in the process not leaving much scope for differentiation in contributions. In that case, political circles might well have the feeling after some time has elapsed of being back where they started. The history of reinsuring those benefits which had been withdrawn from the Disablement Benefits Act is a reason for drawing attention to this risk.

With the partial privatisation of the first two and six weeks of the Sickness Benefits Act, the phenomenon of collective reinsurance occurred on a much less large scale. These events have served to strengthen my conviction that partial privatisation may lead to better results than full privatisation. But partial privatisation is by no means a halfway measure. In order to avoid everything being insured collectively via collective agreements, it would seem to me essential to observe two conditions in privatising the Sickness Benefits Act and the Disablement Benefits Act:

- privatise only those elements of the system for which the Government is willing to accept the market's rules of play;

- limit the volume to a scale appropriate to the financial capacity of the companies that have to assume the risks.

Only if these conditions are satisfied can society's support be assumed for accepting in the event of private insurance that the aspect of being provided for must yield to the rules of the insurance contract.

It is wise to make these aspects explicit right at the start of the operation and to arrive at clear agreements on the scope and the rules which will apply in the new situation. Failing this, there is the risk that we will be embarking on an overhaul of the system which will get bogged down half way through. The point is therefore to properly demarcate the boundaries between what should be insured publicly and what may be insured privately. 